\title{
Comparison of the Apical Sealing Ability of Calcium Silicate-Based Sealer and Resin-Based Sealer Using the Fluid-Filtration Technique
}

\author{
Widcha Asawaworarit ${ }^{\mathrm{a}}$ Prapaporn Yachor ${ }^{\mathrm{a}}$ Kanittha Kijsamanmith ${ }^{\mathrm{b}}$ \\ Noppakun Vongsavan ${ }^{b}$
}

Departments of a Operative Dentistry and Endodontics and ${ }^{\mathrm{b}}$ Oral Biology, Faculty of Dentistry, Mahidol University, Bangkok, Thailand

\section{Key Words}

Apical sealing ability · Fluid filtration · Calcium

silicate-based sealer $\cdot$ Resin-based sealer

\begin{abstract}
Objective: The aim was to evaluate the apical sealing ability of tricalcium silicate-based (MTA Fillapex ${ }^{\circledR}$ ) and resin-based (AH Plus ${ }^{\circledR}$ ) sealers at $24 \mathrm{~h}, 7$ days and 4 weeks. Materials and Methods: Thirty-four extracted human upper anterior teeth were used. All the teeth were sectioned to leave the root $15 \mathrm{~mm}$ long, and then all the roots were instrumented using a set of ProTaper ${ }^{\circledR}$ rotary instruments. Four roots were selected randomly as controls, and the remaining 30 were randomly divided into 2 groups of 15 each: MTA Fillapex and gutta-percha (group 1) and AH Plus and gutta-percha (group 2) using a warm vertical compaction technique. The apical sealing ability of the filled root canal was measured using the fluid-filtration method with $200 \mathrm{~mm} \mathrm{Hg}(26.67 \mathrm{KPa})$ above atmospheric pressure at $24 \mathrm{~h}, 7$ days and 4 weeks. The apical microleakage of the 2 groups was compared using Student's t test. $p<0.05$ was considered statistically significant. $\boldsymbol{R e}$ sults: The mean apical microleakage in group 1 at $24 \mathrm{~h}, 7$ days and 4 weeks was $1.01 \pm 0.24,0.43 \pm 0.07$ and $0.24 \pm 0.08$ $\mathrm{nl} / \mathrm{s}$. The corresponding values in group 2 were $1.15 \pm 0.40$, $0.32 \pm 0.09$, and $0.38 \pm 0.10 \mathrm{nl} / \mathrm{s}$. MTA Fillapex had signifi-
\end{abstract}

cantly more leakage than AH Plus at 7 days, but at 4 weeks, MTA Fillapex showed a significantly better sealing ability than AH Plus $(p<0.05)$. Conclusions: In this study, the tricalcium silicate-based sealer promoted proper sealing when used for filling the root canals.

(c) 2016 S. Karger AG, Basel

\section{Introduction}

It is generally believed that the technical quality of root canal filling may have an impact on the treatment outcome because of the sealing capability that the fixing material provides against bacteria, microbial byproducts and tissue fluid $[1,2]$. Gutta-percha has been used as root canal filling material for almost 150 years, in addition to the use of sealer, essential for obtaining a fluid-tight seal between the dentinal wall and the gutta-percha [3]. Resinbased sealers such as AH Plus ${ }^{\circledR}$ are very commonly used as they do not release formaldehyde after setting [4], have long-term dimensional stability and expansion properties and are considered as the 'gold standard' root canal sealer $[5,6]$. However, it has been demonstrated that these sealers are undesirable due to their biological activity and cytotoxicity in cultures $[7,8]$. Tricalcium silicatebased cements, universally referred to as mineral trioxide

\begin{tabular}{ll}
\hline KARGER & $\begin{array}{l}\text { ( ) 2016 S. Karger AG, Basel } \\
1011-7571 / 16 / 0256-0561 \$ 39.50 / 0 \quad \text { Karger }\end{array}$ \\
$\begin{array}{l}\text { E-Mail karger@karger.com } \\
\text { www.karger.com/mpp }\end{array}$ & $\begin{array}{l}\text { Thisis an Open Access article licensed under the terms of the } \\
\text { Creative Commons Attribution-NonCommercial 3.0 Un- } \\
\text { ported license (CC BY-NC) (www.karger.com/OA-license), } \\
\text { applicable to the online version of the article only. Distribu- } \\
\text { tion permitted for non-commercial purposes only. }\end{array}$
\end{tabular}

Dr. Kanittha Kijsamanmith

Department of Oral Biology, Faculty of Dentistry

Mahidol University, 6 Yothi Street

Bangkok 10400 (Thailand)

E-Mail kanittha.kij@mahidol.ac.th 
aggregate (MTA) cements have revealed interesting biological properties, both in the laboratory $[9,10]$ and in in vitro tests [11], and are more biocompatible than common endodontic sealer $[7,8]$.

In 2010, a new endodontic sealer based on MTA, MTA Fillapex ${ }^{\circledR}$, was developed by Angelus (Londrina/Parana/ Brazil) and was launched commercially [12]. This product is more stable than calcium hydroxide, constantly releases calcium ions [13] and maintains a $\mathrm{pH}$ which elicits antibacterial effects [14]. MTA Fillapex is a sealer presented in a paste/paste system and is composed of MTA, resins, bitmuth trioxide, nanoparticulated silica and pigment $[14,15]$. Its manufacturer claims that it has excellent radiopacity, easy handling and a good working time $[14,15]$. However, only a few studies have investigated the sealing ability of MTA Fillapex $[16,17]$. Therefore, the objective of this study was to determine the apical sealing ability of MTA Fillapex and AH Plus in vitro at $24 \mathrm{~h}, 7$ days and 4 weeks.

\section{Materials and Methods}

The experiments were carried out on 34 extracted maxillary anterior human teeth with single, straight root canals and fully developed apices. Exclusion criteria were resorptive defects, dental caries, cracks and open apices. The experiments were approved by the Institutional Review Board of the Faculty of Dentistry/Faculty of Pharmacy, Mahidol University, Bangkok, Thailand. All the teeth were cleaned to remove any attached debris and were then stored in $0.1 \%$ thymol solution until use. The crowns of all the teeth were removed at the cementoenamel junction using a low-speed saw (Isomet ${ }^{\circledR}$, Buehler, Lake Bluff, Ill., USA) with water coolant, before adjusting all the roots to $15 \mathrm{~mm}$ in length. Canal patency was determined by passing a size- $10 \mathrm{~K}$-file (Densply Maillefer, Ballaigues, Switzerland) through the apical foramen. Working lengths were established $0.5 \mathrm{~mm}$ short of the apical foramen, and the roots were instrumented using Protaper ${ }^{\circledR}$ (Densply Maillefer) NiTi rotary instruments. The coronal and middle portions of the root canals were flared by SX, $S_{1}$, and $S_{2}$, before the apical portion was instrumented with $\mathrm{F}_{1}, \mathrm{~F}_{2}, \mathrm{~F}_{3}, \mathrm{~F}_{4}$ and $\mathrm{F}_{5}$. Between the use of each file, the root canals were irrigated with $5 \mathrm{ml}$ of $2.5 \% \mathrm{NaOCl}$ solution.

On completion of instrumentation, the root canals were irrigated with $2 \mathrm{ml}$ of $17 \%$ EDTA acid followed by $5 \mathrm{ml}$ of $2.5 \%$ $\mathrm{NaOCl}$ to remove the smear layer. All irrigating solutions were delivered through 25-gauge needles and the root canals were dried with paper points (Diadent, Almere, Netherlands).

Four teeth were selected randomly as controls and the remaining 30 were randomly divided into 2 experimental groups of 15 teeth each: MTA Fillapex (group 1) and AH Plus (group 2).

Group 1. The roots were filled with MTA Fillapex (Angelus Indústria de Produtos Odontologicos S/A, Londrina, PR, Brazil) and gutta-percha (Densply Maillefer) using a warm vertical compaction technique. MTA Fillapex was mixed according to the manufacturer's instructions and placed into the root canals with an $\mathrm{F}_{5}$ file. The $\mathrm{F}_{5}$ gutta-percha cone that fitted and gave tug-back at the working length was chosen. The apical section of this cone was coated with sealer and then slowly inserted into the root canal until the working length was reached. The cone was then seared off coronally with a heated instrument and packed. The remaining space was back-filled using a B\&L SuperEndo Gun (B\&L SuperEndo Beta starter kit in white; Sure-DENT Corp., Gyeonggi-do, Korea) until the canal was completely filled with gutta-percha (B\&L Beta gutta-percha pellet soft type; Sure-DENT Corp.).

Group 2. The roots were filled with AH Plus (Densply DeTrey, Konstanz, Germany) and gutta-percha (Densply Maillefer) using a warm vertical compaction technique. AH Plus was mixed according to the manufacturer's instructions and the root canals were filled in the manner described for group 1.

Positive Control Group. The roots $(\mathrm{n}=2)$ were filled with an $\mathrm{F}_{5}$ taper master gutta-percha cone, using the warm vertical compaction technique without sealer.

Negative Control Group. The roots $(\mathrm{n}=2)$ were filled with an $\mathrm{F}_{5}$ taper master gutta-percha cone using the warm vertical compaction technique without sealer. The roots were then totally coated with 2 layers of nail polish, including the apical foramina, to ensure that there was no leak of fluid movement anywhere within the device.

After obturation of the root canals, all specimens were stored in gauze dampened with sterile saline and enclosed in a humidifier at $37^{\circ} \mathrm{C}$ and $100 \%$ humidity.

\section{Measurement of Apical Microleakage}

Apical microleakage was measured using the fluid filtration method described by Timpawat et al. [18] (fig. 1). Each root was mounted in a cap and collar made from a plastic rod (ICI Plastic Division, Welwyn Garden City, UK), which had been sealed into a stainless steel tube (No. 18 hypodermic needle). The tube was connected to a glass capillary (internal diameter $300 \mu \mathrm{m}$, Supracaps cat. No. 709007) to accommodate the rate of flow under different pressures. The pressure of the system was controlled by attaching the tubing from the capillary to a mercury manometer. Apical microleakage was detected by observing the movement of a small air bubble introduced into the capillary. The measurements of fluid flow were recorded with a positive pulpal pressure of 200 $\mathrm{mm} \mathrm{Hg}(26.67 \mathrm{KPa})$. Three consecutive measurements were taken to calculate the mean flow rate. Apical microleakage was defined as the fluid flow rate in nanoliters per second $(\mathrm{nl} / \mathrm{s})$.

\section{Statistical Analysis}

The mean apical microleakage of each sealer at $24 \mathrm{~h}$, at 7 days and at 4 weeks were compared using one-way repeated-measures ANOVA and Tukey's test for pair-wise comparisons. $p<0.05$ was considered statistically significant. The apical microleakages of the 2 groups were compared using Student's t test. $\mathrm{p}<0.05$ was considered statistically significant.

\section{Results}

The overall apical microleakage of the negative control group was 0 , indicating no leakage in the device, while the positive control group was immeasurably high or displayed $100 \%$ leakage. The mean apical microleakage of 


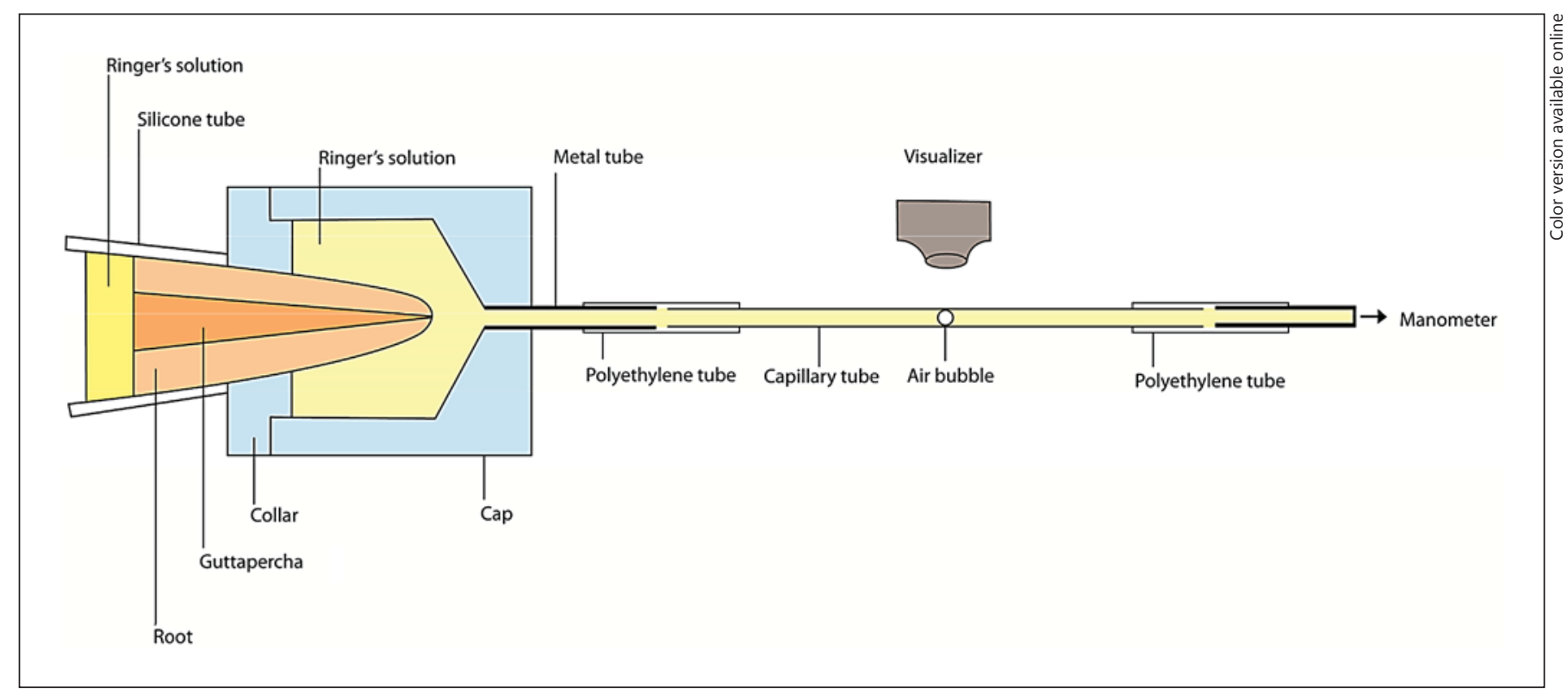

Fig. 1. Diagram of the experimental setup for the measurement of apical microleakage using the fluid filtration technique.

MTA Fillapex at $24 \mathrm{~h}, 7$ days and 4 weeks was $1.01 \pm 0.24$, $0.43 \pm 0.07$ and $0.24 \pm 0.08 \mathrm{nl} / \mathrm{s}$, respectively. The corresponding values of AH Plus were $1.15 \pm 0.40,0.32 \pm 0.09$ and $0.38 \pm 0.10 \mathrm{nl} / \mathrm{s}$. One-way repeated-measures ANOVA showed a significant reduction in the apical microleakage of MTA Fillapex at 24 h, 7 days and 4 weeks (p < 0.05). The apical microleakage of AH Plus at $24 \mathrm{~h}$ was higher than at 7 days and at 4 weeks ( $\mathrm{p}<0.001$ ), but no significant difference between 7 days and 4 weeks was observed ( $p>0.05)$. In a comparison of the 2 groups, there was no significant difference at $24 \mathrm{~h}$, but AH Plus had less leakage than MTA Fillapex at 7 days $(\mathrm{p}<0.05)$. At 4 weeks, however, AH Plus had more leakage than MTA Fillapex ( $p<0.001$; fig. 2).

\section{Discussion}

The results of this study based on the fluid filtration technique demonstrated that MTA Fillapex had an apical sealing ability superior to AH Plus after 4 weeks when used for filling the root canal with a warm vertical compaction technique. This may be explained by the different composition of these 2 sealers. MTA Fillapex is a hydraulic tricalcium silicate-based sealer composed of MTA, salicylate resin, natural resin, bismuth oxide and silica, which can set in a moist environment [16]. AH Plus is a

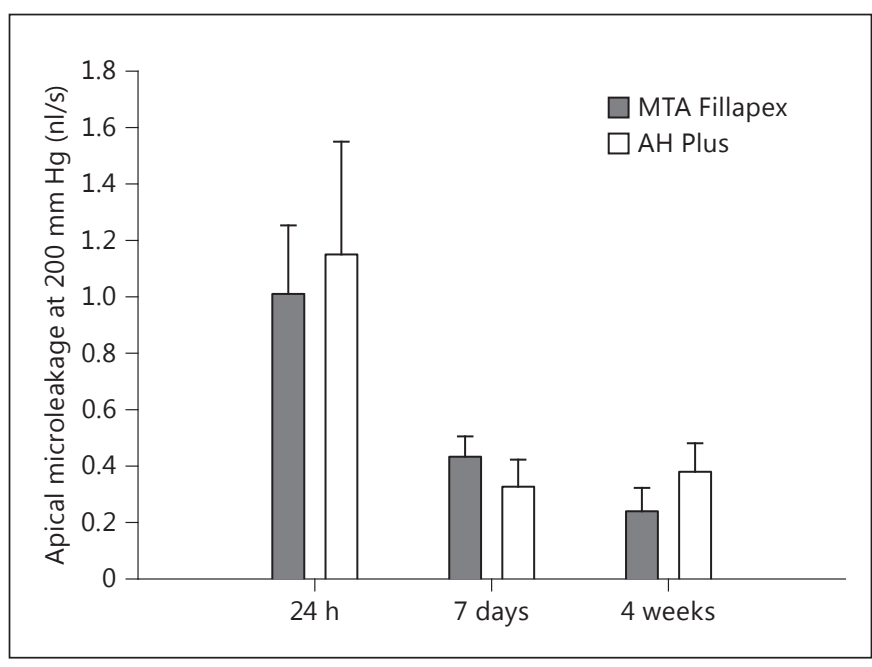

Fig. 2. Bar graph of mean apical microleakage values for both experimental groups at $24 \mathrm{~h}, 7$ days and 4 weeks. The error bars indicate $1 \mathrm{SD}$ from the mean.

hydrophobic, resin-based sealer composed of epoxy-bisphenol resin and adamantine amine. Traces of moisture (i.e. wet dentine) could negatively affect the sealing ability of AH Plus to the dentine wall [3]. In this study, the fluid filtration technique was used to evaluate the apical sealing ability of MTA Fillapex and AH Plus because this 
technique allows quantitative measurements of leakage in root canals with the advantage that the root specimens can be measured repeatedly over a period of time without damaging them [19].

In this study, the apical microleakage of both MTA Fillapex and AH Plus had the highest leakage at $24 \mathrm{~h}$, which is similar to the results obtained by Gandolfi and Prati [20] and Zhang et al. [21]. This could be due to their slow setting properties. This study also indicated that there was a significant reduction in the apical microleakage of MTA Fillapex after 7 days and at 4 weeks, because MTA contains calcium oxide, which might react with water or tissue fluids to form calcium hydroxide which can dissociate into calcium and hydroxyl ions. The calcium ions react with the carbon dioxide in the tissues and form calcium carbonate granulations presenting as calcite crystals [22]. This phenomenon could reduce marginal gaps and porosities and increase the retention of the cement [23]. The MTA hydration forms a sticky calcium silicate hydrate gel that improves the sealing ability of MTA cement over time [20].

When compared to AH Plus, MTA Fillapex had more leakage at 7 days but at 4 weeks, MTA Fillapex had the better sealing ability. A probable explanation is that the MTA sealer could reduce the leakage to the root canal wall over time by the continuous formation of hydration products which react with dentinal calcium and phosphate ions and lead to the formation of calcium phosphate precipitate [20]. Moreover, the final irrigation with $\mathrm{NaOCl}$ performed at the end of instrumentation left an alkaline environment suitable for calcium silicate cement hydration which could have improved the sealing ability of the MTA-based root canal sealer [24]. In contrast, a final sodium hypochlorite flush after EDTA can remove organic material from the exposed dentine surface, which may lead to the decrease in the strength of the epoxy resin bond to the dentine and the resulting increase in leakage in specimens filled with AH Plus [25].

The dissolution of a sealer may induce the formation of gaps between root canal and filling materials, resulting in an increase in leakage. A previous study demonstrated that the solubility of MTA Fillapex was statistically lower than AH Plus over 1-28 days $(\mathrm{p}<0.05)$ [26]. Thus, the lower solubility of MTA Fillapex led to the better sealing ability of MTA over time. AH Plus showed higher water sorption values than MTA Fillapex at 1,7,14 and 28 days [26]. Water diffusion into resin cements can lead to the deterioration of the physical and mechanical properties, thereby decreasing the life-expectancy of the interfaces by hydrolysis and the formation of microcracks [27].
However, the water absorption property of MTA Fillapex could be beneficial because it promotes a slight expansion of the material, which might promote proper sealing [12]. MTA setting in a moist environment results in the hydration of anhydrous mineral oxide compounds to produce the swelling of calcium silicate hydrate gel and various hydration products, which, in turn, produces volume expansion and might enhance the seal and minimize leakage $[28,29]$. This is one possible reason for our finding that the sealing ability of MTA Fillapex had improved after 24 h, 7 days and 4 weeks.

The flow characteristics of endodontic sealers might also determine how effectively they obturate the voids, irregularities and accessory canals. The MTA Fillapex sealer exhibited a higher flow but a lower film-thickness than the AH Plus sealer, when using a warm, vertically compacted gutta-percha obturation technique [30]. Thus, the higher flow of MTA Fillapex may result in better sealing of the root canal and its irregularities.

\section{Conclusions}

In this study, MTA Fillapex had significantly more leakage than AH Plus 1 week after filling. However, after 4 weeks, it showed significantly better sealing ability than AH Plus. Hence, MTA Fillapex could promote proper sealing when used for filling root canals.

\section{Acknowledgement}

This study was supported by the Faculty of Dentistry, Mahidol University, Bangkok, Thailand.

\section{Disclosure Statement}

There were no conflicts of interest.

References ence of the quality of endodontic treatment and coronal restorations on the prevalence of apical periodontitis in a Turkish Cypriot population. Med Princ Pract 2013;22:173-177.

2 Ureyen Kaya B, Kececi AD, Guldas HE, et al: A retrospective radiographic study of coronal-periapical status and root canal filling quality in a selected adult Turkish population. Med Princ Pract 2013;22:334-339.

-3 Ørstavik D: Materials used for root canal obturation; technique, biological and clinical testing. Endod Topics 2005;12:25-38.

Asawaworarit/Yachor/Kijsamanmith/ Vongsavan
Med Princ Pract 2016;25:561-565 DOI: 10.1159/000450577 
4 Leonardo MR, Silva LA, Filho MT, et al: Release of formaldehyde by 4 endodontic sealers. Oral Surg Oral Med Oral Pathol Oral Radiol Endod 1999;88:221-225.

$>5$ Ørstavik D, Nordahl I, Tibballs JE: Dimensional change following setting of root canal sealer materials. Dent Mater 2001;17:512519.

6 Brackett MG, Martin R, Sword J, et al: Comparison of seal after obturation techniques using a polydimethylsiloxane-based root canal sealer. J Endod 2006;32:1188-1190.

7 Huang TH, Tai KW, Chou MY, et al: Cytotoxicity of resin, zinc oxide-eugenol, and calcium hydroxide-based root canal sealers on human periodontal ligament cells and permanent V79 cells. Int Endod J 2002;35:153-158.

$>8$ Sousa CJA, Montes CRM, Pascon EA, et al: Comparison of the intraosseous biocompatibility of AH Plus, EndoREZ, and Epiphany root canal sealers. J Endod 2006;32:656-662.

$>9$ Gandolfi MG, Pagani S, Perut F, et al: Innovative silicate-based cements for endodontics: a study of osteoblast-like cell response. Biomed Mater Res 2008;87:477-486.

10 Gandolfi MG, Perut F, Ciapetti G, et al: New Portland cement-based materials for endodontics mixed with articaine solution: a study of cellular response. J Endod 2008;34: 39-44.

$\checkmark 11$ Gomes-Filho JE, de Faria MD, Bernabé PF, et al: Mineral trioxide aggregate but not lightcure mineral trioxide aggregate stimulated mineralization. J Endod 2008;34:62-65.

12 MTA Fillapex Endodontic Sealer. Angelus. http://www.angelusdental.com/img/arquivos/mta_fillapex_technical_profile_download.pdf (accessed November 9, 2013).
13 Gomes-Filho JE, Watanabe S, Bernabé PFE, et al: A mineral trioxide aggregate sealer stimulated mineralization. J Endod 2009;35:256260.

14 Morgental RD, Vier-Pelisser FV, Oliveira SD, et al: Antibacterial activity of two MTA-based root canal sealers. Int Endod J 2011;44:11281133.

15 Taşdemir T, Er K, Çelik D, et al: Bond strength of calcium silicate-based sealers to dentine dried with different techniques. Med Princ Pract 2014;23:373-376.

16 Gomes-Filho JE, Moreira JV, Watanabe S, et al: Sealability of MTA and calcium hydroxidecontaining sealers. J Appl Oral Sci 2012;20: 347-351.

17 Sönmez IS, Oba AA, Sönmez D, et al: In vitro evaluation of apical microleakage of a new MTA-based sealer. Eur Arch Paediatr Dent 2012;13:252-255.

18 Timpawat S, Vongsavan N, Messer HH: Effect of removal of the smear layer on apical microleakage. J Endod 2001;27:351-353.

19 Wu MK, Wesselink PR, Boersma J: A 1-year follow-up study on leakage of four root canal sealers at different thickness. Int Endod J 1995;28:185-189.

20 Gandolfi MG, Prati C: MTA and F-doped MTA cements used as sealers with warm gutta-percha. Long-term study of sealing ability. Int Endod J 2010;43:889-901.

21 Zhang W, Li Z, Peng B: Assessment of a new root canal sealer's apical sealing ability. Oral Surg Oral Med Oral Pathol Oral Radiol Endod 2009; 107:e79-e82.
22 Holland R, Souza V, Nery MJ, et al: Reaction of rat connective tissue to implanted dentin tubes filled with mineral trioxide aggregate or calcium hydroxide. J Endod 1999;25:161166.

23 Iacono F, Gandolfi MG, Huffman B, et al: Push-out strength of modified Portland cements and resins. Am J Dent 2010;23:43-46.

24 Namazikhah MS, Nekoofar MH, Sheykhrezae MS, et al: The effect of $\mathrm{pH}$ on surface hardness and microstructure of mineral trioxide aggregate. Int Endod J 2008;41:108-116.

25 Neelakantan P, Subbarao C, Subbarao CV, et al: The impact of root dentine conditioning on sealing ability and push-out bond strength of an epoxy resin root canal sealer. Int Endod J 2011;44:491-498.

26 Vitti RP, Prati C, Silva EJNL, et al: Physical properties of MTA Fillapex sealer. J Endod 2013;39:915-918.

27 Sideridou I, Tserki V, Papanastasiou G: Study of water sorption, solubility and modulus of elasticity of light-cured dimethacrylatesbased dental resins. Biomaterials 2003;24: 1381-1387.

28 Hawley M, Webb TD, Goodell GG: Effect of varying water-to-powder ratios on the setting expansion of white and gray mineral trioxide aggregate. J Endod 2010;36:1377-1379.

29 Storm B, Eichmiller FC, Tordik PA, et al: Setting expansion of gray and white mineral trioxide aggregate and Portland cement. J Endod 2008;34:80-82.

30 Camilleri J: Sealers and warm gutta-percha obturation techniques. J Endod 2015;41:7278. 